\title{
44237 - TWO CASES OF HEART-LIVER TRANSPLANT ON CARDIOPULMONARY BYPASS
}

\author{
Trevor Hennessey, McGill University Health Center, Montreal, QC, Canada; \\ Kevin Lachapelle, McGill University Health Center; \\ Patrick Ergina, McGill University Health Center; \\ Peter Metrakos, McGill University Health Center; \\ Thomas Schricker, McGill University Health Center;
}

\section{INTRODUCTION:}

We report the first two Canadian cases of combined heart-liver transplantation (CHLT) carried out on complete cardio-pulmonary bypass (CPB) with full anticoagulation.

\section{CLINICAL FEATURES:}

Consent for disclosure of these cases was obtained from both patients. Patient 1 was a 53 yearold man with familial hypertrophic cardiomyopathy who developed cirrhosis secondary to right ventricular failure. His past medical history included atrial fibrillation with sino-atrial ablation and pacemaker placement. He had normal LV function with severe RV diastolic dysfunction and congestive heart failure (NYHA class IV). Patient 2 was a 57 year-old man with hypertrophic restrictive cardiomyopathy with reduced LV function of 25-30\% (NYHA class III heart failure), congestive hepatitis with cirrhosis, atrial fibrillation, ICD, chronic renal failure and mild COPD. Both patients were taking coumadin.

While donor suitability was assessed, the patients had monitors placed including a pulmonary artery catheter, arterial line, a 2nd cordis to serve as a volume transfusion line and two 14 gauge IV's. An intravenous anesthetic consisting of midazolam and sufental was utilized with pancuronium for muscle relaxation. 2 million units of aprotinin as a bolus followed by 0.5 million units.hour-1 was started prior to CPB. All abdominal dissections were performed without completing the hepatectomy. Subsequently CPB was initiated using bicaval cannulation via the superior vena cava and femoral vein with standard aortic cannulation. The recipient's heart was explanted and bicaval heart transplantation was performed. The recipient hepatectomy was then completed and donor liver implanted with the entire transplantation occurring on CPB with beating heart. Biliary anastomosis was completed off pump. CPB and organ ischemic times are listed below. Following weaning from CPB, patient 1 required infusions of 16 mcg.min-1 norepinephrine and 5 mcg.min- 1 epinephrine while patient 2 required 5 mcg.min-1 epinephrine and $0.5 \mathrm{mcg} . \mathrm{kg}-1 . \mathrm{min}-1$ milrinone. Intraoperatively patient 1 had $2.6 \mathrm{~L}$ estimated blood loss (EBL) and received $2 \mathrm{~L}$ cell saver blood, $3 \mathrm{~L}$ of crystalloid, 3 units packed red blood cells (PRBC), 10 units platelets, 10 units of cryoprecipitate, 12 units of fresh frozen plasma (FFP) and 2 units of fibrinogen. Patient 2 had $3 \mathrm{~L} \mathrm{EBL}$ and received $2 \mathrm{~L}$ cell saver blood, $3.5 \mathrm{~L}$ of crystalloid, 2 units PRBC, 23 units platelets, 20 units of cryoprecipitate and 8 units of FFP. 


\begin{tabular}{|l|c|c|c|c|}
\hline & \multirow{2}{*}{$\begin{array}{c}\text { CPB time } \\
\text { (min) }\end{array}$} & $\begin{array}{c}\text { Cross-clamp } \\
\text { time (min) }\end{array}$ & \multicolumn{2}{|c|}{$\begin{array}{c}\text { Ischemic } \\
\text { Time (min) }\end{array}$} \\
\cline { 4 - 5 } & & & Heart & Liver \\
\hline Patient 1 & 197 & 73 & 185 & 288 \\
\hline Patient 2 & 188 & 53 & 201 & 300 \\
\hline
\end{tabular}

\section{CONCLUSIONS:}

By performing the liver transplantation on $\mathrm{CPB}$ we were able to easily manage the hemodynamic and metabolic impact of caval unclamping during the liver re-perfusion period. While this was at the cost of a longer pump run, this time when used for a longer cardiac re-perfusion stage resulted in a heart that was easily weaned from bypass with minor vasopressor and inotropic support.

\section{REFERENCES:}

Ann Surg 1985 202: 667-672

Can J Anesth 2004 51: 1045-1046 